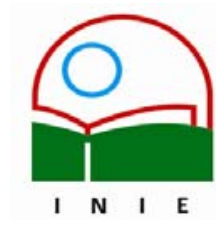

\title{
LOS SIGNIFICADOS PEDAGÓGICOS DEL AULA, DE LA ESCUELA Y DEL SISTEMA EDUCATIVO: UN APORTE DE LA INVESTIGACIÓN CUALITATIVA A LA EDUCACIÓN COSTARRICENSE ${ }^{1}$
}

\author{
Dra. Natalia Campos Saborío ${ }^{2}$
}

\section{Introducción}

Desde 1986, un equipo interdisciplinario del INIE, integrado por la investigadoras: Margarita Brenes psicóloga, Natalia Campos, curriculista, Nidia García, especialista en Artes del Idioma y Marta Rojas, filóloga se interesó por investigar los procesos educativos, desde la óptica de la cotidianeidad del aula y de la escuela, con el fin de captar su dinámica tal cual sucedía diariamente, en el salón de clase y en la escuela e interpretarla, al escudriñar los significados que la sustentaban y así contar con una visión del problema educativo más global y cercano a su quehacer, dónde se gestan los aprendizajes de los estudiantes ,que según los resultados de las pruebas de rendimiento académico aplicadas por este instituto en la década de los ochenta, mostraron ser escasos y poco equitativos, en términos de instituciones y de regiones más 0 menos favorecidas, económicamente.

En consecuencia, el equipo de investigadoras centró su atención, en el encuentro del docente con el estudiante en el aula y en la gestión de director en la escuela. En el primer estudio de interacción verbal dimos una mirada a profundidad a las interacciones verbales del docente con los estudiantes y de estos entre sí, en el segundo, indagamos el manejo de categorías en el aula, tan importantes y universales como el espacio y el tiempo. También, nos ocupamos de investigar el tratamiento de los contenidos programáticos de los planes de estudio oficiales y del

\footnotetext{
${ }^{1}$ Conferencia Congreso Internacional de Investigación Educativa: "Investigar para transformar" Instituto de Investigación en Educación-Universidad de Costa Rica, COSTA RICA. 2 de febrero de 2005

${ }^{2}$ Directora del INIE, en el período 1989-1994.
} 
tratamiento de los comportamientos de maestros y estudiantes en el aula.

En aras de profundizar el trabajo del aula observado en los dos estudios anteriores, la tercera investigación versó sobre el quehacer de la escuela fue así, como llevamos a cabo la etnografía de la institución escolar.

En este artículo, realizo una lectura crítica de los hallazgos de las tres investigaciones citadas. Expongo los significados pedagógicos develados del quehacer del aula y de la escuela,( lo que se hace) y del discurso de documentos oficiales del Sistema Educativo Costarricense. Luego, presento las contradicciones develadas entre lo que dicen hacer los docentes en el aula, la directora de la escuela en estudio, y el discurso de documentos del sistema educativo y lo que realmente se hace en los ámbitos citados. Por último, aporto una reflexión en torno a las contradicciones apuntadas.

\section{Los significados pedagógicos del aula, de la institución escolar, del sistema educativo}

El análisis de estos significados se derivan de los resultados de los estudios aula, y de la institución escolar citados y de aquellos examinados en documentos del sistema educativo.

\subsection{El aula}

El docente "un domador y no un formador"

El maestro se apodera del lenguaje, lo emplea para controlar y no para formar. El estudio de interacción verbal en el aula reportó los siguientes hallazgos: de un total de 5000 interacciones verbales recabadas, $65 \%$ la iniciaron los docentes, $25 \%$ los estudiantes para comunicarse con los docentes, y $10 \%$ los estudiantes para interaccionar entre ellos. El $65 \%$ de las interacciones verbales de los maestros, las 
utilizaron, en orden descendente, para: dar instrucciones, controlar comportamientos de los estudiantes, tratar el contenido de los programas educativos, y sólo un $1 \%$ de las interacciones verbales para referirse a asuntos personales y sociales. En síntesis, tenemos una educación, centrada en el docente, directiva, controladora, transmisora de contenidos e indiferente a la humanidad de los estudiantes, su ser, su existencia, su colectivo.

\section{El maestro se apodera del espacio en el aula, se propasa en el uso de la metodología del regaño y del control, somete a los estudiantes a un tiempo importante de la clase a realizar actividades de aprendizaje de poca calidad.}

La investigación del proceso enseñanza y aprendizaje en el aula nos revela que: el aula es territorio del docente, el tiene su área de acción, al frente del salón de clase, dónde se ubica el escritorio, y la pizarra, desde dónde dirige y controla lo que sucede allí. Así también, se desplaza libremente entre las filas de pupitres, organización espacial comúnmente empleada, mientras los estudiantes permanecen confinados al metro cuadrado que ocupan sus pupitres, y si éstos se movilizan dentro del aula, sin el permiso de la maestra, hablan entre ellos o intercambian objetos, se les reprende con el regaño, la amenaza, el boleteo, el envío a la directora para su correspondiente sanción.

En el metro cuadrado, territorio del estudiante, éste generalmente, copia ejercicios, tareas, esquemas, entre otros, de la pizarra, del libro de texto, o de lo que dicta la maestra. Un registro de observación de aula de 80 minutos que se detalla así: 10 minutos para rutinas, 5 para introducción del tema, 45 para la copia, y 20 para la revisión, muestra cómo la mayoría del tiempo (45 minutos) se emplean en una actividad tan poco productiva para el aprendizaje, como la copia, mientras que la introducción del tema, se le dedica solamente 5 minutos (Rojas, García, Brenes, 1992).

De esta caracterización tenemos que: el docente es el dueño del territorio del aula, el controlador de lo que sucede en ella, el responsable de que el estudiante piense que el tiempo se puede utilizar para mantenerse ocupado aunque su trabajo no le depare disfrute, ni aprendizajes de calidad .Parece que el mensaje es siga las instrucciones, manténgase bajo las normas, y no tiene problema. 


\subsection{La escuela}

La escuela como contexto mediato del aula no trasciende su rol reproductor a uno transformador de la educación.

El tercer estudio etnográfico acerca de una institución escolar a profundidad denominada escuela \#1, y de 5 escuelas más, nos presenta una gestión administrativa centrada en: la administración de recursos materiales y un manejo de trámites-papeles oficiales: recaudar fondos, comprar recursos didácticos, revisar dineros del patronato, evaluar el personal y dar seguimiento a nombramientos. Aunque, la directora, estimuló y facilitó la capacitación de las docentes en el manejo de aula, durante la realización del estudio, no se involucró en el proceso. Referente a las relaciones humanas en esa escuela, los docentes caracterizan a su directora como una persona que no ha logrado establecer un clima de confianza en sus relaciones personales con los maestros en la escuela, su función está revestida de formalidad, de legalismo, usa el poder en forma vertical. (Zúñiga, Rojas, Campos, 2002).

De este tercer estudio se concluye que la directora es un administradora educativa de la planta física, del trámite, de la aplicación de la normativa ministerial, más que de la acción transformadora de la escuela, pues facilitó la capacitación de las docentes, pero mantuvo distancia en el proceso, lo cuál no le permitió comprender el intento de las docentes a su cargo, por generar aprendizajes significativos en el aula y por el establecimiento de un clima institucional de relaciones humanas cálidas y de mutua confianza.

\subsection{El popurrí teórico del sistema educativo}

La Política Educativa hacia el Siglo XXI y el Proyecto EDU.2005, planteó como sustento teórico, los enfoques curriculares: el racionalismo, el humanismo, el constructivismo y obvió el tecnológico de fundamento conductista, el cuál es de mayor aplicación en el sistema, pues la medición educativa (exámenes de sexto grado, de noveno año y de bachillerato) se basan en él. Esta es una contradictoria mezcla de enfoques que no vamos a discutir aquí, pero si cabe señalar que hay diferente visión epistemológica entre los enfoques racionalista, 
tecnológico, y constructivista, el cual lleva implícito el humanismo. En los primeros el sujeto, por medio de la razón aprehende al objeto y es la razón la que tiene la verdad absoluta, y en el segundo, la razón es un vehículo para construir la verdad entre la interacción del sujeto con el objeto y otros sujetos, en consecuencia hay tantas verdades como sujetos y objetos exista.

Con este eclecticismo facilista, es difícil para el docente en el aula, saber cuándo y por qué aplicar el conductismo, el racionalismo, el humanismo y el constructivismo, creo que lo que tiene claro, de lo observado en el aula, es controlar y transmitir contenidos programáticos para ser medidos, por los exámenes.

\section{Las contradicciones entre lo que se dice que se hace y lo que se hace en el aula, la escuela, y el sistema educativo.}

\subsection{En el aula}

De los resultados de estudios del aula que nos ocupan, y desde la óptica de lo que sucede en el salón de clase, señalamos que: el protagonismo del docente es exacerbado: domina el espacio verbal y territorial del aula, hay mas visos de autoritarismo que de autoridad en el manejo del aula, su misión se centra en la transmisión del contenido de los programas de estudio ,en función de la medición por medio de exámenes en el aula y de aquellos que aplica el Ministerio de Educación Pública, lo cuál es antitesis del aprendizaje liberador y creador del ser humano. Sin embargo, cuando se le preguntó a los docentes, acerca de cómo desean formar a los niños, las maestras expresaron que quieren formar niños felices, libres, sin temor, amados, comprendidos, protegidos, y respetados.( Garcìa, Rojas, Campos,2002).

\subsection{En la escuela}

Los resultados de la etnografía de la escuela desde su cotidianeidad, nos muestra a una directora que facilita la capacitación de las docentes, pero que no se involucra en el proceso de un asunto medular de la educación, el mejoramiento profesional de los docentes, garante, en gran medida de mejores aprendizajes de los niños. Su gestión administrativa la absorbe, la administración de lo material, el trámite 
y los reglamentos y usa el poder en forma vertical. No obstante, la directora se percibe como ejecutiva, sensible a los problemas que aquejan a la institución, de trato justo y amable con el personal docente y con los padres de familia, promotora del mejoramiento profesional, capaz de lograr metas, y enfrentar dificultades, persistente, y luchadora.

\subsection{El sistema Educativo}

El sistema educativo impulsa en su discurso, el constructivismo, cuyos elementos aparecen en los programas de estudio, se predican en las capacitaciones y en el proceso de formación de los docentes, se integran en los libros de texto, pero paralelamente el Departamento de Control de Calidad del Ministerio de Educación Pública ejecuta los exámenes, de corte conductista, a las poblaciones de estudiantes de primaria y secundaria del país sin distingo de las diferencias culturales de las zonas, en dónde habitan, de su estatus económico, social, y étnico convirtiendo a la medición educativa en un instrumento homogenizador que reduce la educación en el aula a un proceso reproductor de contenidos abstractos y poco pertinentes culturalmente, todo ello contrario al constructivismo que hace énfasis en un proceso creador, plural, divergente, y respetuoso de los aprendizajes adquiridos previamente por los estudiantes en sus experiencias de vida familiar y comunitaria.

\section{A manera de cierre}

Notamos, entonces que la práctica educativa en el aula, en la escuela, en el sistema educativo sufre como dicen algunos autores de esquizofrenia, pues hay dos realidades separadas que conviven en su práctica educativa. Parece haber una fractura al interno de los educadores, por un lado expresamos el deseo de llevar nuestra misión formadora de una manera sana y liberadora y terminamos haciéndola represiva y por ende poco sana.

Las causas de este fenómeno son complejas y variadas, una de ellas se relaciona con las visiones de mundo que concursan en el pensamiento y en el quehacer de los educadores. 
Aflora un mundo de la vida (Berticelli, 2000, citado por Campos, 2003) que los docentes llevamos en nuestro interior, en dónde damos importancia a: "la naturaleza simbólica del ser humano, a su experiencia comunicativa e intersubjetiva, a sus diferentes verdades, reales en sus mentes y corazones" (Campos, 2003). Sin embargo, a los docentes, nos aprisiona, la visión del mundo del sistema (Berticelli, 2000, citado por Campos 2003), el que se caracteriza por "su materialismo, aquí se privilegia la producción económica y se violenta la simbólica, se ejerce el control y la imposición". (Campos, 2003).

En el análisis de los significados pedagógicos que nos ocupan. palpamos el mundo de la vida cuando: los docentes expresan que desean formar " niños felices, libres, sin temor, amados, comprendidos, y respetados"; la directora dice que es" sensible a los problemas que aquejan la institución, y que da trato justo y amable al personal docente"; el discurso de documentos del sistema educativo habla de un enfoque constructivista que privilegia una formación integral del educando y estimula su capacidad creadora al brindarle condiciones para un aprendizaje autónomo. No obstante, en el actuar de los docentes en el aula, de la directora en la escuela en estudio, y de las autoridades educativas, la acción educativa, se torna controladora y reproductiva, reflejando así, el mundo del sistema.

Es imperante retomar el pensamiento filosófico y educativo de pensadores e que abogan por la visión del mundo de la vida en la educación costarricense, pues en el mundo actual, experimentamos la cosificación del ser humano, por ello, cito palabras de Joaquín García Monge, expresadas en el discurso de la tercera graduación de maestros de la Escuela Normal de Heredia, en 1917, en dónde manifiesta que: "la escuela no es sombría, no es dolorosa, ni es ingrata...la escuela no es el aula en cuyas paredes se retuerce el eco desesperante en dónde agonizan las miradas del niño que busca el horizonte...no es el edificio que aprisiona o que fastidia ,ni los maestros que se hacen la guerra mutuamente, ni los métodos mas o menos practicables que nos traten de imponer...la escuela es el espacio dónde dos seres dialogan en un punto del camino ,dos seres que persiguen un más allá intangible. La escuela es la libertad de pensamiento, la obra, la palabra. La escuela es el imperio de la alegría, el templo de los justos, el paraíso de los buenos...el maestro no es un domador sino un modelador...no es verdugo, no es empleado que gana sueldos para comer, no es un 
miserable...es poderoso porque juega con el infinito, trabaja con el alma. Demuele y transforma. Demuele principios tóxicos y absurdos, sistemas nocivos y creencias falsas. Reforma temperamentos enfermos, organismos raquíticos, instituciones torcidas y construye sociedades sanas, justas y fuertes... El maestro no es un domador es un transformador". (García Monge, documento mimeografeado)

\section{Bibliografía}

Brenes F. Margarita, Campos S., Natalia, Garcia L., Nidia, Rojas. P., Marta. (1998). The development of longitudinal model for teaching training. Applided etnographic reseach in urban lowincome Elementary school in Costa Rica. Educational Cualitative Rearch in Latin America. Gary Anderson and Martha Montero- Sieburth (eds.). New York: Garland Publishing Inc.

Campos, S., Natalia. (1991). Estilos de enseñanza-aprendizaje en aulas de escuelas ubicadas en zonas urbano-marginales. Revista Educación. 15 (2): 39-47.

(2000). La mirada Comprometida del Maestro: La observación participante. Revista Espiga de la UNED. Año 1 (2): 9-37, Julio / Diciembre.

(2003). El docente Investigador: Su génesis Teórica y sus Rasgos. Revista Educación. 27(2): 39-43.

. (2003). Nuestra labor de mirar al otro. Revista Educación. 27(1): 231-232,

- (1997). Política Educativa hacia el Siglo XXI: un análisis de su misión. Revista Educación. 21 (1): 23-28.

Campos S., Natalia, Rojas P., Marta. (1993). De la caracterización microetnográfica del aula escolar al diseño de un plan de capacitación. Revista Educación. 17, (2): 111-118. 
(1994). Caracterización de procesos enseñanza - aprendizaje, a partir del análisis de interacción verbal en el aula costarricense. Revista Káñina. XVIII (2): 141-157.

García L., Nidia, Rojas P., Marta, Campos S., Natalia, Brenes F., Margarita. (1991). Training Teachers in urban-marginal city schools: an ethnographic study in Costa Rica. Journal of Global Education. England, University of York.

García L., Nidia, Rojas. P., Marta, Campos S., Natalia. (2002). La Administración Escolar para el cambio y mejoramiento de las instituciones educativas. San José, Costa Rica: Editorial de la Universidad de Costa Rica.

García Monge, Joaquín. (1917). Documento mimeografiado.

Rojas P., Marta, García L., Nidia, Brenes F, Margarita. Funciones del lenguaje. Revista Educación. 16 (1): 45-56.

Rojas P., Marta, García L., Nidia, Brenes F., Margarita. (1992). Conocimiento, Participación y Cambio. El Uso del tiempo en el aula. San José, Costa Rica: Editorial de la Universidad de Costa Rica. 